\title{
Dynamic Nuclear Polarization Enhancement of 200 at 21.15 T Enabled by 65 kHz Magic Angle Spinning
}

Pierrick Berruyer, Snædís Björgvinsdóttir, Andrea Bertarello, Gabriele Stevanato, Yu Rao, Ganesan Karthikeyan, Gilles Casano, Olivier Ouari, Moreno Lelli, Christian Reiter, Frank Engelke, and Lyndon Emsley*

Cite This: J. Phys. Chem. Lett. 2020, 11, 8386-8391

Read Online

ACCESS | Lلll Metrics \& More | 回 Article Recommendations | st Supporting Information

ABSTRACT: Solid-state nuclear magnetic resonance under magic angle spinning (MAS) enhanced with dynamic nuclear polarization (DNP) is a powerful approach to characterize many important classes of materials, allowing access to previously inaccessible structural and dynamic parameters. Here, we present the first DNP MAS experiments using a $0.7 \mathrm{~mm}$ MAS probe, which allows us to reach spinning frequencies of $65 \mathrm{kHz}$, with microwave irradiation, at $100 \mathrm{~K}$. At the highest magnetic field available for DNP today $(21.1 \mathrm{~T})$, we find that the polarizing agent HyTEK2 provides DNP enhancements as high as 200 at a spinning rate of 65 $\mathrm{kHz}$ at $100 \mathrm{~K}$, and BDPA yields an enhancement of 106 under the same conditions. Fast spinning rates enable excellent DNP performance, but they also yield unprecedented ${ }^{1} \mathrm{H}$ resolution under DNP conditions. We report well-resolved ${ }^{1} \mathrm{H}$-detected ${ }^{1} \mathrm{H}-{ }^{13} \mathrm{C}$ and ${ }^{1} \mathrm{H}-{ }^{15} \mathrm{~N}$ correlation spectra of microcrystalline histidine $\cdot \mathrm{HCl} \cdot \mathrm{H}_{2} \mathrm{O}$.

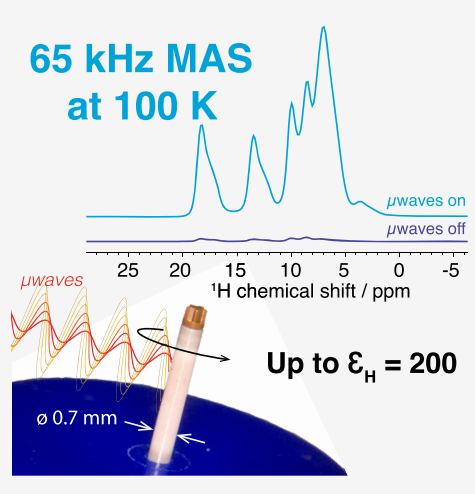

F or value in analytical chemistry, sensitivity and spectral resolution are cornerstone parameters of solid-state nuclear magnetic resonance (SSNMR) experiments. Dynamic nuclear polarization (DNP) is a powerful technique to dramatically increase the sensitivity of NMR by transfer of electron spin polarization to nearby nuclear spins upon microwave $(\mu \mathrm{w})$ irradiation. ${ }^{1}$ In solid-state NMR, the combination of high magnetic field and fast magic angle spinning (MAS) is often a requirement to allow the study of complex systems and to implement sophisticated multidimensional experiments. State-of-the-art commercial NMR instrumentation uses magnetic fields of up to $28 \mathrm{~T}(1.2 \mathrm{GHz})$ and MAS probes that can spin samples to $120 \mathrm{kHz}$ at room temperature using $0.7 \mathrm{~mm}$ diameter rotors. Such spinning regimes significantly improve ${ }^{1} \mathrm{H}$ NMR resolution on samples from small crystalline pharmaceuticals to fully protonated protein assemblies. $^{2-4}$ There is therefore tremendous interest in combining these approaches with DNP. DNP MAS experiments are more demanding as they usually require cryogenic temperatures $(\approx 100 \mathrm{~K})$ to obtain reasonable saturation of the electron spin transition. In 2016, Chaudhari et al. reported DNP MAS experiments at $40 \mathrm{kHz}$ MAS rates using $1.3 \mathrm{~mm}$ rotors, ${ }^{5}$ where faster MAS led to significantly longer coherence lifetimes in ${ }^{29} \mathrm{Si}$ spectra. They then discovered that, very importantly, under certain conditions DNP enhancements increased significantly as the sample spinning rate increased. ${ }^{6,7}$ They also showed that fast spinning yielded ${ }^{27} \mathrm{Al}$ spectra that were free of sidebands or spectral distortions. Wang et al. have shown the possibility of using ${ }^{1} \mathrm{H}$ detection in this context. ${ }^{8}$ In particular, ${ }^{1} \mathrm{H}$-detected ${ }^{1} \mathrm{H}-{ }^{89} \mathrm{Y}$ DNP HETCOR at $40 \mathrm{kHz}$ MAS surpassed the sensitivity of DNP HETCOR recorded using $3.2 \mathrm{~mm}$ rotors at a lower spinning rate.

Here we present the first DNP MAS experiments using a 0.7 $\mathrm{mm}$ MAS probe. This allows us to reach spinning frequencies of $65 \mathrm{kHz}$, with $\mu \mathrm{w}$ irradiation, at $100 \mathrm{~K}$ and at a field of 21.15 $\mathrm{T}$. We report the performance, at very fast MAS, of BDPA in 95\% deuterated orthoterphenyl (OTP- $\left.d_{95 \%}\right)$ and HyTEK2 in 1,1,2,2-tetrachloroethane (TCE). In both, we find that enhancements continue to increase significantly with increasing spinning rates, and we obtain enhancement factors of up to 200 for HyTEK2. Beyond the good DNP performance, we also report the highest directly detected ${ }^{1} \mathrm{H}$ resolution in DNP MAS SSNMR spectra observed so far.

In 2014, Can et al. used the carbon-centered radical BDPA in a polystyrene matrix to obtain significant proton DNP enhancements $\left(\varepsilon_{\mathrm{H}}\right)$ using either Overhauser effect $(\mathrm{OE})$ or solid effect (SE). Interestingly, OE DNP scaled positively with the external magnetic field from $9.4 \mathrm{~T}\left(\varepsilon_{\mathrm{H}}=14\right)$ to $18.8 \mathrm{~T}\left(\varepsilon_{\mathrm{H}}\right.$ $=20){ }^{9}$ and later enhancements of $\varepsilon_{\mathrm{H}}=65$ at $9.4 \mathrm{~T}$ and $\varepsilon_{\mathrm{H}}=$

Received: August 15, 2020

Accepted: September 10, 2020

Published: September 22, 2020 


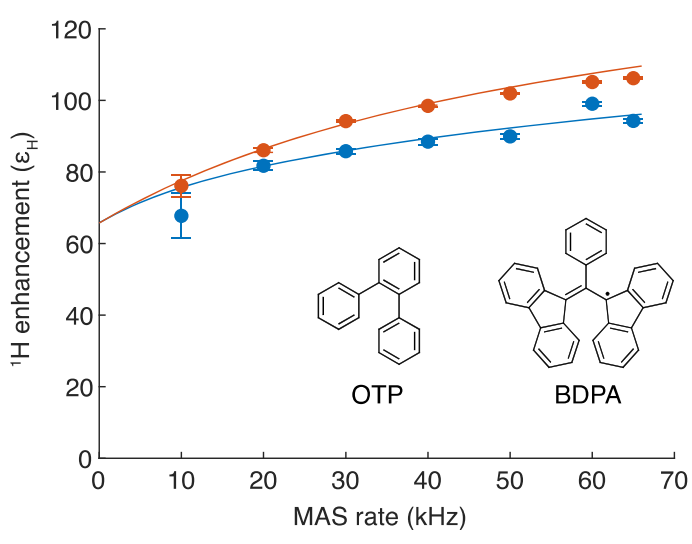

Figure 1. ${ }^{1} \mathrm{H}$ DNP enhancements measured for a $60 \mathrm{mM}$ frozen solution of BDPA in OTP- $d_{95 \%}$ at MAS rates of up to $65 \mathrm{kHz}$. Measurements were taken with polarization delays of $10 \mathrm{~s}$ (blue) and $75 \mathrm{~s}$ (orange) at each spinning frequency. The error bars are calculated from the estimated error based on the signal-to-noise ratio of the $\mu \mathrm{w}$ ON and OFF spectra (see the Supporting Information for details). The blue and orange lines correspond to the simulated DNP enhancements in both cases, based on the source-sink relayed DNP model (see the Supporting Information for details regarding the simulations). ${ }^{6}$ The OTP and BDPA structures are shown.

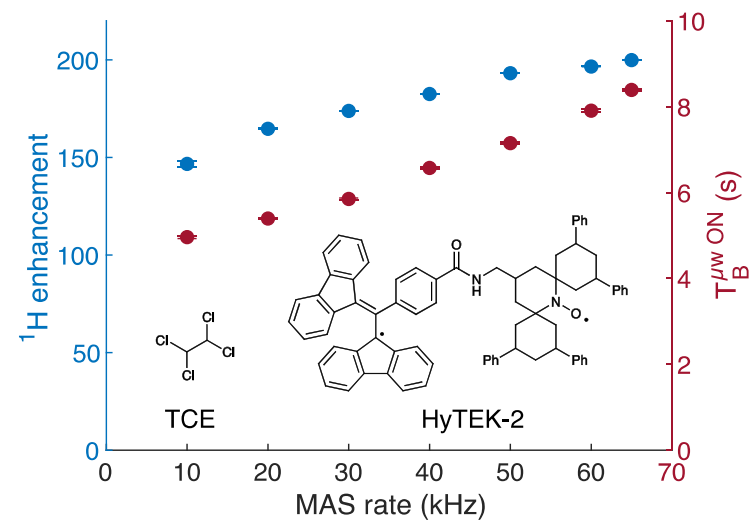

Figure 2. ${ }^{1} \mathrm{H}$ DNP enhancements (blue) and ${ }^{1} \mathrm{H}$ DNP buildup times in seconds (purple) for a $32 \mathrm{mM}$ solution of HyTEK2 in 1,1,2,2tetrachloroethane (TCE) as a function of the MAS rate. The error bars of the ${ }^{1} \mathrm{H}$ enhancement are estimated from the signal-to-noise ratio of the $\mu \mathrm{w}$ ON and OFF spectra, and the error bars of the buildup times are the error of the fit (see the Supporting Information for details). HyTEK2 and TCE molecules are represented in the figure.

75 at $18.8 \mathrm{~T}$ were reported by using a 95\% deuterated orthoterphenyl (OTP- $d_{95 \%}$ ) matrix. ${ }^{10}$ Later, an enhancement $\varepsilon_{\mathrm{H}}=73$ was reported using a BDPA/OTP- $d_{95 \%}$ mixture at $21.15 \mathrm{~T}^{11}$ All of these experiments were performed at moderate sample spinning rates using $3.2 \mathrm{~mm}$ rotors at between $8 \mathrm{kHz}^{9,10}$ and $12.5 \mathrm{kHz}^{11}$ In 2017, OE DNP with BDPA in OTP- $d_{95 \%}$ was investigated at fast magic angle spinning using $1.3 \mathrm{~mm}$ rotors spinning at $\leq 40 \mathrm{kHz}$ in an 18.8 $\mathrm{T}$ magnet, ${ }^{7}$ where it was reported that the ${ }^{1} \mathrm{H}$ enhancement ramped up from 23 at $0.5 \mathrm{kHz}$ MAS to 105 at $40 \mathrm{kHz}$ MAS. Thus, OE DNP with BDPA in OTP- $d_{95 \%}$ at both high field and fast MAS appeared to be a system of choice for performing
DNP measurements using very fast MAS in $0.7 \mathrm{~mm}$ rotors at $21.15 \mathrm{~T}$. At $100 \mathrm{~K}$, the $0.7 \mathrm{~mm}$ rotors can stably spin at rates of up to $65 \mathrm{kHz}$. Although $0.7 \mathrm{~mm}$ rotors can spin stably up to $120 \mathrm{kHz}$ at room temperature, at $100 \mathrm{~K}$ fluid dynamics of the cold nitrogen gas limit the maximum rate. Notably, the density of $\mathrm{N}_{2(\mathrm{~g})}$ is $\sim 3$ times higher at $100 \mathrm{~K}$ than at $298 \mathrm{~K}$, and the speed of sound is slower by a factor $2 .{ }^{12}$ (In principle, this could be mitigated by, for example, spinning using helium gas, but this is technically not straightforward.) Spinning stability at $65 \mathrm{kHz}$ and $100 \mathrm{~K}$ is usually very reliable and stable in the range of $\pm 9 \mathrm{~Hz}$ (see Figure S4).

Figure 1 shows the ${ }^{1} \mathrm{H}$ DNP enhancement of a $60 \mathrm{mM}$ solution of BDPA in OTP- $d_{95 \%}$. The sample was prepared following the method described in ref 10 . Following on from the observations made at $\leq 40 \mathrm{kHz}$, here we see that the ${ }^{1} \mathrm{H}$
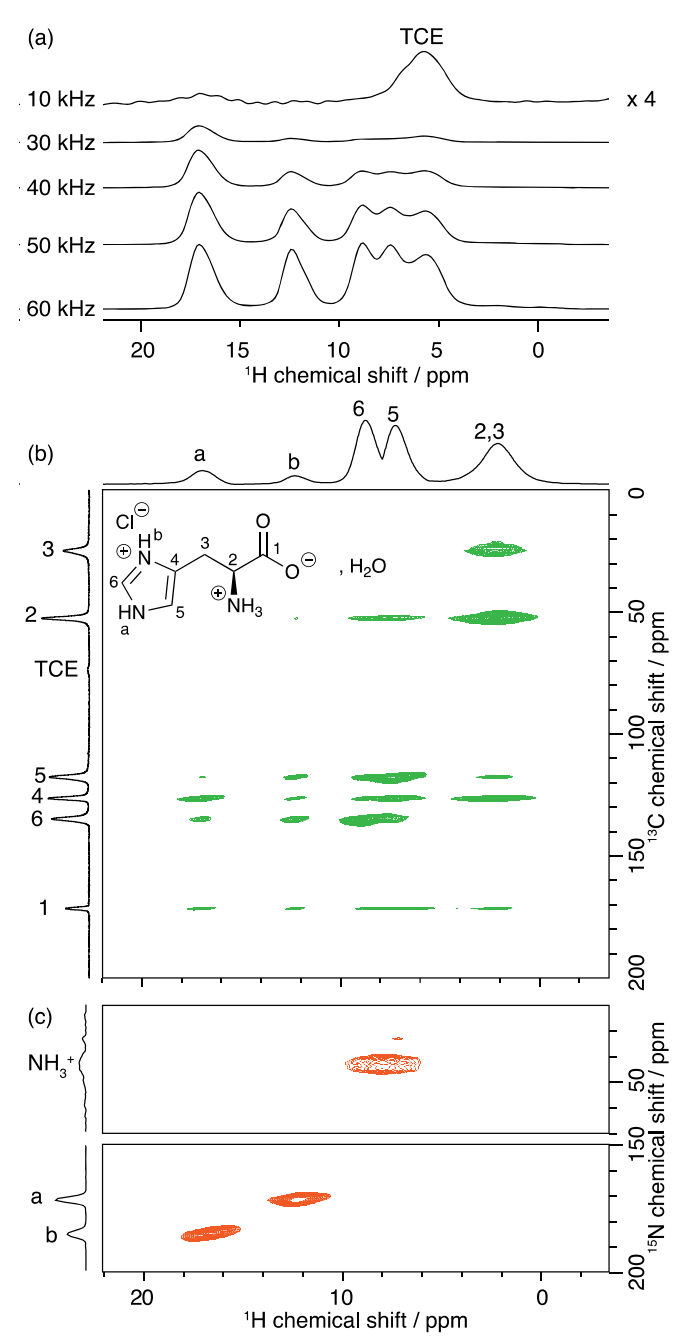

Figure 3. (a) $900 \mathrm{MHz}$ DNP enhanced ${ }^{1} \mathrm{H}$ spectra at different MAS rates between 10 and $60 \mathrm{kHz}$ of $\left[\mathrm{U}-{ }^{13} \mathrm{C},{ }^{15} \mathrm{~N}\right]$ histidine $\cdot \mathrm{HCl} \cdot \mathrm{H}_{2} \mathrm{O}$ impregnated with $32 \mathrm{mM}$ HyTEK2 in TCE. The spectra were all recorded with a $3 \mathrm{~ms}$ total spin echo prior to acquisition for solvent suppression. ${ }^{45}$ Note that the spectrum at $10 \mathrm{kHz}$ is dominated by the solvent signal. (b) ${ }^{1} \mathrm{H}-{ }^{13} \mathrm{C}$ and (c) ${ }^{1} \mathrm{H}-{ }^{15} \mathrm{~N}{ }^{1} \mathrm{H}$-detected DNP HETCOR spectra of the same sample spinning at $62.5 \mathrm{kHz}$. For the sake of clarity, the signal-free region between 70 and $150 \mathrm{ppm}$ of the ${ }^{15} \mathrm{~N}$ dimension of panel $\mathrm{c}$ is not shown. $\mathrm{H} 2 / 3$ signals, clearly visible on panel $b$, are not visible in panel a as they do not survive the spin echo used for solvent suppression. See the Supporting Information for detailed acquisition parameters. 
enhancement continues to increase as the MAS frequency increases to $65 \mathrm{kHz}$, reaching a maximum of $\varepsilon_{\mathrm{H}}=106$. Although Figure 1 reports a maximum enhancement of 106, we have been able to reach $\varepsilon_{\mathrm{H}}=128$ at $65 \mathrm{kHz}$ MAS with a different sample. We attribute this difference to the quality of glass formation upon freezing the sample, which is a recurrent feature in many DNP matrices, including OTP. ${ }^{13-16}$ At $65 \mathrm{kHz}$ MAS, we measure a buildup time $\left(T_{\mathrm{b}, \mathrm{on}}\right)$ of $58 \mathrm{~s}$, and the enhancements were determined with a polarization (recycle) delay of $1.3 \times T_{\mathrm{b}, \text { on }}=75 \mathrm{~s}$ (orange dots in Figure 1). We also measured the ${ }^{1} \mathrm{H}$ enhancements with a polarization delay of 10 $\mathrm{s}$ and observed enhancements consistently lower than for the longer recycle delay (blue dots in Figure 1). This is a clear signature of ${ }^{1} \mathrm{H}-{ }^{1} \mathrm{H}$ spin diffusion relaying hyperpolarization among the ${ }^{1} \mathrm{H}$ nuclei in the OTP matrix. ${ }^{1,18}$ It is possible to rationalize this behavior using the source-sink spin diffusion model proposed in ref 7 . This model hypothesizes that the detected DNP behavior results from the flow of hyperpolarization from the BPDA/OTP- $d_{95 \%}$ source matrix to dilute sinks (e.g., paramagnetic impurities). Using this model, the enhancements with polarization delays of 10 and $75 \mathrm{~s}$ were simulated across the whole range of spinning rates from 0 to 65 $\mathrm{kHz}$. The simulated enhancements are reported in Figure 1 (plain lines) and fit very well to the experimental enhancement data. The details of the simulation model are given in the Supporting Information. The spin diffusion model explains both why $\varepsilon_{\mathrm{H}}$ increases when the MAS rate increases at a constant polarizing delay and why for a given MAS rate $\varepsilon_{\mathrm{H}}$ increases when the polarization delay increases from 10 to $75 \mathrm{~s}$. The results give additional very strong support to the original source-sink model.?

The temperature of the sample in the rotor was monitored at each MAS rate using the $T_{1}\left({ }^{79} \mathrm{Br}\right)$ of a $\mathrm{KBr}$ crystal added to the rotor. ${ }^{19}$ The internal temperature under $\mu \mathrm{w}$ irradiation increases from $95 \mathrm{~K}$ at $10 \mathrm{kHz}$ MAS to $\approx 105 \mathrm{~K}$ at $65 \mathrm{kHz}$ MAS, indicating that the frictional heating induced by MAS in the $0.7 \mathrm{~mm}$ DNP LTMAS probe is only around $10 \mathrm{~K}$. The contribution factor has not been remeasured here as it was previously found to be 1 up to $40 \mathrm{kHz}$ MAS. $^{7}$

Although OE DNP using BDPA provides a large ${ }^{1} \mathrm{H}$ DNP enhancement, the long ${ }^{1} \mathrm{H}$ buildup time prevents it from being an efficient polarizing system. In some cases, flip-back ${ }^{11,20}$ or frequency selective ${ }^{21}$ approaches should be applicable. The rational design of radicals performing OE DNP is still very challenging, which slows development of better OE DNP. ${ }^{22}$ While there is great interest in OE DNP, ${ }^{23}$ it does not appear here to be the polarizing system of choice under these conditions.

On the contrary, cross-effect (CE) DNP has been extensively studied and many design parameters have been discovered $^{15,24-29}$ and theorical models proposed, ${ }^{30-38}$ allowing us today to tailor the structures of CE polarizing agents and thus optimize their performance. Unfortunately, CE polarizing agents that perform very well at moderate magnetic fields (e.g., AMUPOL) scaled unfavorably when going to higher magnetic fields (see Table S1). ${ }^{6,25,39}$ Capitalizing on the work of $\mathrm{Hu}$ et al., ${ }^{32}$ Mathies et al. introduced the concept of mixed biradicals in 2015 in which a TEMPO-like moiety was tethered to a trityl radical. $^{40}$ In particular, the performance of the resulting TEMTriPol-1 scaled favorably with the magnetic field between 5 and $14.1 \mathrm{~T}$, yielding ${ }^{1} \mathrm{H}$ enhancements of 60 at $5 \mathrm{~T}, 87$ at $14.1 \mathrm{~T}$, and 65 at $18.8 \mathrm{~T}$, which was attributed to the strength of the exchange interaction between the trityl radical and the nitroxide. ${ }^{40}$ Capitalizing on the previous concept of decorated binitroxides to provide longer electron relaxation times, Wisser et al. proposed a series of mixed BDPA-nitroxide biradicals and evaluated their performance at both high field (up to 21.15 T) and fast MAS (up to $40 \mathrm{kHz}$ using a $1.3 \mathrm{~mm}$ rotor). ${ }^{6}$ In particular, HyTEK2 yields ${ }^{1} \mathrm{H}$ enhancements of 185 at $18.8 \mathrm{~T}$ and $40 \mathrm{kHz}$ MAS in a $1.3 \mathrm{~mm}$ rotor which was, so far, the highest DNP enhancement reported at high magnetic field and fast MAS. ${ }^{6}$

Figure 2 plots the ${ }^{1} \mathrm{H}$ DNP enhancement and the ${ }^{1} \mathrm{H}$ DNP build-up time as a function of the MAS rate obtained with a 32 mM HyTEK2 solution in TCE. We measured $\varepsilon_{\mathrm{H}}=147$ at 10 $\mathrm{kHz}$, which then increases almost linearly to 200 at the maximum MAS rate of $65 \mathrm{kHz}$.

At the same magnetic field shown in a $3.2 \mathrm{~mm}$ rotor, enhancements of 64 at $10 \mathrm{kHz}$ were previously reported. We attribute the improvement of the performance between 0.7 and $3.2 \mathrm{~mm}$ rotors at the same spinning speed to better penetration of the $\mu \mathrm{w}$. An analogous difference was observed previously between 3.2 and $1.3 \mathrm{~mm}$ rotors at the same MAS rate. ${ }^{5,6} \mathrm{We}$ also made the same observation with a $10 \mathrm{mM}$ AMUPOL in a $6 / 3 / 1(\mathrm{v} / \mathrm{v} / \mathrm{v})$ glycerol $-d_{6} / \mathrm{D}_{2} \mathrm{O} / \mathrm{H}_{2} \mathrm{O}$ solution, and the results are listed in Table $\mathrm{S} 1$.

As reported in ref 6, the combination of fast MAS and high magnetic field with the mixed radical nitroxide-BDPA HyTEK2 allows us to reach unprecedented DNP performance at this magnetic field; the increase with MAS rate is again attributed to decoupling of the polarizing bath from polarization sinks, as for the BDPA/OTP- $d_{95 \%}$ example mentioned above. We note that prior to measurement, the sample was degassed of dissolved $\mathrm{O}_{2}$ using freeze-thaw cycles in the probe. ${ }^{41,42}$ This is always necessary when using TCE as a DNP solvent; degassing here allows us to increase the ${ }^{1} \mathrm{H}$ DNP enhancement (measured at $20 \mathrm{kHz}$ MAS) by $66 \%$ after four freeze-thaw cycles. The temperature of the sample was monitored on the basis of longitudinal relaxation rate $T_{1}\left({ }^{79} \mathrm{Br}\right)$ of a $\mathrm{KBr}$ crystal incorporated in the sample ${ }^{19}$ (see Figure $\mathrm{S} 2$ for details). Similarly, to what we observed above with BDPA/ OTP- $d_{95 \%}$, very fast MAS induces sample heating of only $\sim 10$ $\mathrm{K}$, and here in addition $\mu \mathrm{w}$ irradiation induces another $10 \mathrm{~K}$ heating due to the use of TCE that absorbs some $\mu \mathrm{w}$. The contribution factor has not been remeasured here; it was previously found to be constant at 0.71 between 5 and $40 \mathrm{kHz}$ MAS, ${ }^{6}$ and we believe this value can be extrapolated to $65 \mathrm{kHz}$ MAS. In total, our data demonstrate that the HyTEK2 radical is a very efficient polarizing agent for very fast MAS DNP at high field. We were able to reach a ${ }^{1} \mathrm{H}$ DNP enhancement of 200 , which is a new record for both a magnetic field of $21.15 \mathrm{~T}$ and the HyTEK2 polarizing agent.

One of the most promising outcomes for NMR with fast MAS (60 kHz and higher) is the achievable ${ }^{1} \mathrm{H}$ resolution, which allows one, for example, to record directly or indirectly ${ }^{1} \mathrm{H}$ NMR spectra without the use of sophisticated ${ }^{1} \mathrm{H}$ homonuclear decoupling schemes. ${ }^{43}$ In DNP MAS, reaching such regime was not possible until now as hardware was limited to $\leq 40 \mathrm{kHz}$. Here, as a proof of concept, we present ${ }^{1} \mathrm{H}$-detected DNP MAS experiments at $65 \mathrm{kHz}$ MAS on a microcrystalline powder of $\left[\mathrm{U}_{-}{ }^{13} \mathrm{C},{ }^{15} \mathrm{~N}\right]$ histidine hydrochloride impregnated with $32 \mathrm{mM}$ HyTEK2 in TCE, at $100 \mathrm{~K}$. In the impregnation approach, the histidine does not dissolve in TCE and the hyperpolarization diffuses from the frozen HyTEK2/ TCE phase to the histidine crystal through spontaneous spin diffusion, as is now well established. ${ }^{17,44}$ HyTEK2/TCE was 
chosen between the two DNP systems benchmarked here as it provides the highest sensitivity gain (in terms of DNP enhancements and build-up times). Figure 3a shows DNPenhanced ${ }^{1} \mathrm{H}$ spectra at different MAS rates. The strong TCE signal was partially suppressed using a spin echo of $3 \mathrm{~ms}$ prior to acquisition. ${ }^{45}$ At $10 \mathrm{kHz}$ MAS, this method of solvent suppression was not efficient enough, and the spectrum is actually dominated by the TCE signal. One can observe both the significant increase in sensitivity and spectral resolution as the spinning frequency is increased. In addition to the increase in the DNP enhancement with HyTEK2 at higher MAS rates, these observations are related to the increase in the ${ }^{1} \mathrm{H}$ coherence lifetime, the decrease in the ${ }^{1} \mathrm{H}$ line width, and the decrease in the number of sidebands as the spin rate increases. $^{43,46}$ The duration of the spin echo for solvent suppression was kept constant (at $3.0 \mathrm{~ms}$ ) between the different MAS rates to compare the intensity between the spectra. The enhancement of the histidine signals in the 20 $\mathrm{kHz}$ spectrum is 41 (note that the sample was not degassed). The enhancement was not measured at $65 \mathrm{kHz}$ for this sample but was previously measured to be $\varepsilon_{\mathrm{H}}=25$ at $35 \mathrm{kHz}$ for the histidine signals and $\varepsilon_{\mathrm{H}}=35$ at $65 \mathrm{kHz}$. The slight asymmetry of the ${ }^{1} \mathrm{H}$ signals is attributed to shimming issues, probably due to the current probe design, which includes an extension of the waveguide into the stator to improve overall performance. ${ }^{47}$

Figure $3 \mathrm{~b}$ shows the two-dimensional (2D) DNP-enhanced ${ }^{1} \mathrm{H}$-detected ${ }^{1} \mathrm{H}-{ }^{13} \mathrm{C}$ HETCOR spectrum and Figure $3 \mathrm{c}$ ${ }^{1} \mathrm{H}-{ }^{15} \mathrm{~N}$ HETCOR spectrum of impregnated $\left[\mathrm{U}-{ }^{13} \mathrm{C},{ }^{15} \mathrm{~N}\right]$ histidine at $62.5 \mathrm{kHz}$ MAS. The HETCOR spectra are fully resolved and allow all of the resonances to be assigned.

In conclusion, we have reported DNP MAS experiments using $0.7 \mathrm{~mm}$ rotors spinning at $65 \mathrm{kHz}$ at a magnetic field of $21.15 \mathrm{~T}$. The enhancements measured for the samples studied here increase with increasing MAS rates. This allows us to obtain the highest enhancements measured at this magnetic field so far. In particular, we found that HyTEK2 can yield a ${ }^{1} \mathrm{H}$ DNP enhancement of 200 at the maximum spinning frequency. We then showed how reaching these spin rates under DNP conditions opens up the possibility of using ${ }^{1} \mathrm{H}$ detected spectra more widely in MAS DNP, and as an example, we obtained resolved DNP-enhanced ${ }^{1} \mathrm{H}$-detected $1 \mathrm{D}$ and $2 \mathrm{D}$ spectra.

\section{ASSOCIATED CONTENT}

\section{(5) Supporting Information}

The Supporting Information is available free of charge at https://pubs.acs.org/doi/10.1021/acs.jpclett.0c02493.

Details of experimental parameters, spin diffusion simulation details, and the DNP performance of the AMUPOL polarizing agent (PDF)

The MatLab code used to perform simulations and the NMR raw data have been deposited at: http://doi.org/ 10.5281 /zenodo.4032323.

\section{AUTHOR INFORMATION}

\section{Corresponding Author}

Lyndon Emsley - Institut des Sciences et Ingénierie Chimiques, Ecole Polytechnique Féderale de Lausanne (EPFL), CH-1015 Lausanne, Switzerland; 이이.org/0000-0003-1360-2572; Email: lyndon.emsley@epfl.ch

\section{Authors}

Pierrick Berruyer - Institut des Sciences et Ingénierie Chimiques, Ecole Polytechnique Féderale de Lausanne (EPFL), CH-1015 Lausanne, Switzerland; 이이.org/0000-0003-1783-6034

Snædís Björgvinsdóttir - Institut des Sciences et Ingénierie Chimiques, Ecole Polytechnique Féderale de Lausanne (EPFL), CH-1015 Lausanne, Switzerland

Andrea Bertarello - Institut des Sciences et Ingénierie Chimiques, Ecole Polytechnique Féderale de Lausanne (EPFL), CH-1015 Lausanne, Switzerland; ㅇorcid.org/0000-00033705-1760

Gabriele Stevanato - Institut des Sciences et Ingénierie Chimiques, Ecole Polytechnique Féderale de Lausanne (EPFL), CH-1015 Lausanne, Switzerland; 이이.org/0000-00030020-1286

Yu Rao - Institut des Sciences et Ingénierie Chimiques, Ecole Polytechnique Féderale de Lausanne (EPFL), CH-1015 Lausanne, Switzerland; 이이.org/0000-0002-9787-5596

Ganesan Karthikeyan - Aix Marseille Univ, CNRS, ICR, 13013 Marseille, France

Gilles Casano - Aix Marseille Univ, CNRS, ICR, 13013

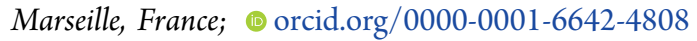

Olivier Ouari - Aix Marseille Univ, CNRS, ICR, 13013 Marseille, France

Moreno Lelli - Magnetic Resonance Center (CERM) and Department of Chemistry "Ugo Schiff", University of Florence, 50019 Sesto Fiorentino, Italy; (i) orcid.org/0000-0002-70422335

Christian Reiter - Bruker Biospin, 76287 Rheinstetten, Germany

Frank Engelke - Bruker Biospin, 76287 Rheinstetten, Germany

Complete contact information is available at:

https://pubs.acs.org/10.1021/acs.jpclett.0c02493

\section{Notes}

The authors declare no competing financial interest.

\section{ACKNOWLEDGMENTS}

P.B., A.B., and G.S. acknowledge Innosuisse, the NCCR Chemical Biology, and the Marie-Skłodowska-Curie program (Grant 796904), respectively, for support. This work was supported by Swiss National Science Foundation Grant 200020_178860.

\section{REFERENCES}

(1) DNP mechanisms. In Emagres; pp 295-338.

(2) Agarwal, V.; Penzel, S.; Szekely, K.; Cadalbert, R.; Testori, E.; Oss, A.; Past, J.; Samoson, A.; Ernst, M.; Bockmann, A.; et al. De novo 3D structure determination from sub-milligram protein samples by solid-state $100 \mathrm{kHz}$ MAS NMR spectroscopy. Angew. Chem., Int. Ed. 2014, 53 (45), 12253-12256.

(3) Andreas, L. B.; Jaudzems, K.; Stanek, J.; Lalli, D.; Bertarello, A.; Le Marchand, T.; Cala-De Paepe, D.; Kotelovica, S.; Akopjana, I.; Knott, B.; et al. Structure of fully protonated proteins by protondetected magic-angle spinning NMR. Proc. Natl. Acad. Sci. U. S. A. 2016, 113 (33), 9187-9192.

(4) Struppe, J.; Quinn, C. M.; Sarkar, S.; Gronenborn, A. M.; Polenova, T. Ultrafast ${ }^{1} \mathrm{H}$ MAS NMR crystallography for natural abundance pharmaceutical compounds. Mol. Pharmaceutics 2020, 17 (2), 674-682.

(5) Chaudhari, S. R.; Berruyer, P.; Gajan, D.; Reiter, C.; Engelke, F.; Silverio, D. L.; Coperet, C.; Lelli, M.; Lesage, A.; Emsley, L. Dynamic nuclear polarization at $40 \mathrm{kHz}$ magic angle spinning. Phys. Chem. Chem. Phys. 2016, 18 (15), 10616-22. 
(6) Wisser, D.; Karthikeyan, G.; Lund, A.; Casano, G.; Karoui, H.; Yulikov, M.; Menzildjian, G.; Pinon, A. C.; Purea, A.; Engelke, F.; et al. BDPA-nitroxide biradicals tailored for efficient dynamic nuclear polarization enhanced solid-state NMR at magnetic fields up to 21.1 T. J. Am. Chem. Soc. 2018, 140 (41), 13340-13349.

(7) Chaudhari, S. R.; Wisser, D.; Pinon, A. C.; Berruyer, P.; Gajan, D.; Tordo, P.; Ouari, O.; Reiter, C.; Engelke, F.; Coperet, C.; et al. Dynamic nuclear polarization efficiency increased by very fast magic angle spinning. J. Am. Chem. Soc. 2017, 139 (31), 10609-10612.

(8) Wang, Z.; Hanrahan, M. P.; Kobayashi, T.; Perras, F. A.; Chen, Y.; Engelke, F.; Reiter, C.; Purea, A.; Rossini, A. J.; Pruski, M. Combining fast magic angle spinning dynamic nuclear polarization with indirect detection to further enhance the sensitivity of solid-state NMR spectroscopy. Solid State Nucl. Magn. Reson. 2020, 101685.

(9) Can, T. V.; Caporini, M. A.; Mentink-Vigier, F.; Corzilius, B.; Walish, J. J.; Rosay, M.; Maas, W. E.; Baldus, M.; Vega, S.; Swager, T. M.; Griffin, R. G. Overhauser effects in insulating solids. J. Chem. Phys. 2014, 141 (6), 064202

(10) Lelli, M.; Chaudhari, S. R.; Gajan, D.; Casano, G.; Rossini, A. J.; Ouari, O.; Tordo, P.; Lesage, A.; Emsley, L. Solid-state dynamic nuclear polarization at 9.4 and $18.8 \mathrm{~T}$ from $100 \mathrm{~K}$ to room temperature. J. Am. Chem. Soc. 2015, 137 (46), 14558-61.

(11) Bjorgvinsdottir, S.; Walder, B. J.; Pinon, A. C.; Yarava, J. R.; Emsley, L. DNP enhanced NMR with flip-back recovery. J. Magn. Reson. 2018, 288, 69-75.

(12) Bouleau, E.; Saint-Bonnet, P.; Mentink-Vigier, F.; Takahashi, H.; Jacquot, J. F.; Bardet, M.; Aussenac, F.; Purea, A.; Engelke, F.; Hediger, S.; et al. Pushing NMR sensitivity limits using dynamic nuclear polarization with closed-loop cryogenic helium sample spinning. Chem. Sci. 2015, 6 (12), 6806-6812.

(13) Viger-Gravel, J.; Berruyer, P.; Gajan, D.; Basset, J. M.; Lesage, A.; Tordo, P.; Ouari, O.; Emsley, L. Frozen acrylamide gels as dynamic nuclear polarization matrices. Angew. Chem., Int. Ed. 2017, 56 (30), 8726-8730.

(14) Barnes, A. B.; De Paepe, G.; van der Wel, P. C. A.; Hu, K. N.; Joo, C. G.; Bajaj, V. S.; Mak-Jurkauskas, M. L.; Sirigiri, J. R.; Herzfeld, J.; Temkin, R. J.; et al. High-field dynamic nuclear polarization for solid and solution biological NMR. Appl. Magn. Reson. 2008, 34 (34), 237-263.

(15) Zagdoun, A.; Casano, G.; Ouari, O.; Schwarzwalder, M.; Rossini, A. J.; Aussenac, F.; Yulikov, M.; Jeschke, G.; Coperet, C.; Lesage, A.; et al. Large molecular weight nitroxide biradicals providing efficient dynamic nuclear polarization at temperatures up to $200 \mathrm{~K}$. J. Am. Chem. Soc. 2013, 135 (34), 12790-12797.

(16) Ong, T. C.; Mak-Jurkauskas, M. L.; Walish, J. J.; Michaelis, V. K.; Corzilius, B.; Smith, A. A.; Clausen, A. M.; Cheetham, J. C.; Swager, T. M.; Griffin, R. G. Solvent-free dynamic nuclear polarization of amorphous and crystalline ortho-terphenyl. J. Phys. Chem. B 2013, 117 (10), 3040-3046.

(17) Pinon, A. C.; Schlagnitweit, J.; Berruyer, P.; Rossini, A. J.; Lelli, M.; Socie, E.; Tang, M. X.; Pham, T.; Lesage, A.; Schantz, S.; et al. Measuring nano- to microstructures from relayed dynamic nuclear polarization NMR. J. Phys. Chem. C 2017, 121 (29), 15993-16005.

(18) van der Wel, P. C. A.; Lewandowski, J. R.; Griffin, R. G. Solidstate NMR study of amyloid nanocrystals and fibrils formed by the peptide gnnqqny from yeast prion protein sup35p. J. Am. Chem. Soc. 2007, 129 (16), 5117-5130.

(19) Thurber, K. R.; Tycko, R. Measurement of sample temperatures under magic-angle spinning from the chemical shift and spin-lattice relaxation rate of $\mathrm{Br}-79$ in $\mathrm{KBr}$ powder. J. Magn. Reson. 2009, 196 (1), 84-87.

(20) Jayanthi, S.; Lupulescu, A. Sensitivity enhancement in 2D double cross polarization experiments under fast MAS by recycling unused protons. Solid State Nucl. Magn. Reson. 2020, 107, 101652.

(21) Wijesekara, A. V.; Venkatesh, A.; Lampkin, B. J.; VanVeller, B.; Lubach, J. W.; Nagapudi, K.; Hung, I.; Gor'kov, P. L.; Gan, Z. H.; Rossini, A. J. Fast acquisition of proton-detected HETCOR solid-state NMR spectra of quadrupolar nuclei and rapid measurement of $\mathrm{NH}$ bond lengths by frequency selective HMQC and RESPDOR pulse sequences. Chem. - Eur. J. 2020, 26 (35), 7881-7888.

(22) Pylaeva, S.; Ivanov, K. L.; Baldus, M.; Sebastiani, D.; Elgabarty, $\mathrm{H}$. Molecular mechanism of overhauser dynamic nuclear polarization in insulating solids. J. Phys. Chem. Lett. 2017, 8 (10), 2137-2142.

(23) Orlando, T.; Dervisoglu, R.; Levien, M.; Tkach, I.; Prisner, T. F.; Andreas, L. B.; Denysenkov, V. P.; Bennati, M. Dynamic nuclear polarization of $\mathrm{C}-13$ nuclei in the liquid state over a $10 \mathrm{~T}$ field range. Angew. Chem., Int. Ed. 2019, 58 (5), 1402-1406.

(24) Hu, K. N.; Yu, H. H.; Swager, T. M.; Griffin, R. G. Dynamic nuclear polarization with biradicals. J. Am. Chem. Soc. 2004, 126 (35), 10844-10845.

(25) Sauvee, C.; Rosay, M.; Casano, G.; Aussenac, F.; Weber, R. T.; Ouari, O.; Tordo, P. Highly efficient, water-soluble polarizing agents for dynamic nuclear polarization at high frequency. Angew. Chem., Int. Ed. 2013, 52 (41), 10858-10861.

(26) Zagdoun, A.; Rossini, A. J.; Gajan, D.; Bourdolle, A.; Ouari, O.; Rosay, M.; Maas, W. E.; Tordo, P.; Lelli, M.; Emsley, L.; et al. Nonaqueous solvents for DNP surface enhanced NMR spectroscopy. Chem. Commun. 2012, 48 (5), 654-656.

(27) Zagdoun, A.; Casano, G.; Ouari, O.; Lapadula, G.; Rossini, A. J.; Lelli, M.; Baffert, M.; Gajan, D.; Veyre, L.; Maas, W. E.; et al. A slowly relaxing rigid biradical for efficient dynamic nuclear polarization surface-enhanced NMR spectroscopy: Expeditious characterization of functional group manipulation in hybrid materials. J. Am. Chem. Soc. 2012, 134 (4), 2284-2291.

(28) Matsuki, Y.; Maly, T.; Ouari, O.; Karoui, H.; Le Moigne, F.; Rizzato, E.; Lyubenova, S.; Herzfeld, J.; Prisner, T.; Tordo, P.; et al. Dynamic nuclear polarization with a rigid biradical. Angew. Chem., Int. Ed. 2009, 48 (27), 4996-5000.

(29) Kubicki, D. J.; Casano, G.; Schwarzwalder, M.; Abel, S.; Sauvee, C.; Ganesan, K.; Yulikov, M.; Rossini, A. J.; Jeschke, G.; Coperet, C.; et al. Rational design of dinitroxide biradicals for efficient cross-effect dynamic nuclear polarization. Chem. Sci. 2016, 7 (1), 550-558.

(30) Kessenikh, A. V.; Lushchikov, V. I.; Manenkov, A. A.; Taran, Y. V. Proton polarization in irradiated polyethylenes. Sov. Phys. Solid State 1963, 5 (2), 321-329.

(31) Maly, T.; Debelouchina, G. T.; Bajaj, V. S.; Hu, K. N.; Joo, C. G.; Mak-Jurkauskas, M. L.; Sirigiri, J. R.; van der Wel, P. C. A.; Herzfeld, J.; Temkin, R. J.; Griffin, R. G. Dynamic nuclear polarization at high magnetic fields. J. Chem. Phys. 2008, 128 (5), 052211.

(32) Hu, K. N.; Bajaj, V. S.; Rosay, M.; Griffin, R. G. High-frequency dynamic nuclear polarization using mixtures of TEMPO and trityl radicals. J. Chem. Phys. 2007, 126 (4), 044512.

(33) Thurber, K. R.; Tycko, R. Theory for cross effect dynamic nuclear polarization under magic-angle spinning in solid state nuclear magnetic resonance: The importance of level crossings. J. Chem. Phys. 2012, 137 (8), 084508.

(34) Mentink-Vigier, F.; Marin-Montesinos, I.; Jagtap, A. P.; Halbritter, T.; van Tol, J.; Hediger, S.; Lee, D.; Sigurdsson, S. T.; De Paepe, G. Computationally assisted design of polarizing agents for dynamic nuclear polarization enhanced NMR: The ASYMPOL family. J. Am. Chem. Soc. 2018, 140 (35), 11013-11019.

(35) Mentink-Vigier, F.; Akbey, U.; Hovav, Y.; Vega, S.; Oschkinat, H.; Feintuch, A. Fast passage dynamic nuclear polarization on rotating solids. J. Magn. Reson. 2012, 224, 13-21.

(36) Corzilius, B. Theory of solid effect and cross effect dynamic nuclear polarization with half-integer high-spin metal polarizing agents in rotating solids. Phys. Chem. Chem. Phys. 2016, 18 (39), 2719027204.

(37) Mance, D.; Gast, P.; Huber, M.; Baldus, M.; Ivanov, K. L. The magnetic field dependence of cross-effect dynamic nuclear polarization under magic angle spinning. J. Chem. Phys. 2015, 142 (23), 234201.

(38) Leavesley, A.; Jain, S.; Kamniker, I.; Zhang, H.; Rajca, S.; Rajca, A.; Han, S. Maximizing NMR signal per unit time by facilitating the ee-n cross effect DNP rate. Phys. Chem. Chem. Phys. 2018, 20 (43), 27646-27657. 
(39) Lund, A.; Casano, G.; Menzildjian, G.; Kaushik, M.; Stevanato, G.; Yulikov, M.; Jabbour, R.; Wisser, D.; Renom-Carrasco, M.; Thieuleux, C.; et al. TinyPols: A family of water-soluble binitroxides tailored for dynamic nuclear polarization enhanced NMR spectroscopy at 18.8 and 21.1 T. Chem. Sci. 2020, 11 (10), 2810-2818.

(40) Mathies, G.; Caporini, M. A.; Michaelis, V. K.; Liu, Y. P.; Hu, K. N.; Mance, D.; Zweier, J. L.; Rosay, M.; Baldus, M.; Griffin, R. G. Efficient dynamic nuclear polarization at $800 \mathrm{MHz} / 527 \mathrm{GHz}$ with trityl-nitroxide biradicals. Angew. Chem., Int. Ed. 2015, 54 (40), 11770-11774.

(41) Kubicki, D. J.; Rossini, A. J.; Purea, A.; Zagdoun, A.; Ouari, O.; Tordo, P.; Engelke, F.; Lesage, A.; Emsley, L. Amplifying dynamic nuclear polarization of frozen solutions by incorporating dielectric particles. J. Am. Chem. Soc. 2014, 136 (44), 15711-15718.

(42) Le, D.; Ziarelli, F.; Phan, T. N. T.; Mollica, G.; Thureau, P.; Aussenac, F.; Ouari, O.; Gigmes, D.; Tordo, P.; Viel, S. Up to $100 \%$ improvement in dynamic nuclear polarization solid-state NMR sensitivity enhancement of polymers by removing oxygen. Macromol. Rapid Commun. 2015, 36 (15), 1416-1421.

(43) Hodgkinson, P. High-resolution H-1 NMR spectroscopy of solids. Annu. Rep. NMR Spectrosc. 2011, 72, 185-223.

(44) Rossini, A. J.; Zagdoun, A.; Hegner, F.; Schwarzwalder, M.; Gajan, D.; Coperet, C.; Lesage, A.; Emsley, L. Dynamic nuclear polarization NMR spectroscopy of microcrystalline solids. J. Am. Chem. Soc. 2012, 134 (40), 16899-16908.

(45) Yarava, J. R.; Chaudhari, S. R.; Rossini, A. J.; Lesage, A.; Emsley, L. Solvent suppression in DNP enhanced solid state NMR. J. Magn. Reson. 2017, 277, 149-153.

(46) Zorin, V. E.; Brown, S. P.; Hodgkinson, P. Origins of linewidth in H-1 magic-angle spinning NMR. J. Chem. Phys. 2006, 125 (14), 144508 .

(47) Purea, A.; Reiter, C.; Dimitriadis, A. I.; de Rijk, E.; Aussenac, F.; Sergeyev, I.; Rosay, M.; Engelke, F. Improved waveguide coupling for $1.3 \mathrm{~mm}$ MAS DNP probes at $263 \mathrm{GHz}$. J. Magn. Reson. 2019, 302, $43-49$. 